\title{
Economia e filosofia: tensão e solução na obra de Adam Smith
}

\author{
Economics and philosophy: tension \\ and solution in Adam Smith's work
}

ANGELA GANEM*

RESUMO: O objetivo deste artigo é mostrar que o trabalho de Adam Smith é realmente unificado, como pode ser visto a partir dos conceitos fundamentais que permeiam tanto a Teoria dos Sentimentos Morais quanto a Riqueza Das Nações. Essa abordagem opõe-se à leitura canônica da obra de Adam Smith, no sentido de que ela une quatro conceitos-chave aninhados paridades em uma cadeia sucessiva de três grupos que se cruzam, levando, finalmente, ao entendimento unificado de sua contribuição, aparentemente disperso em várias partes independentes. Os quatro conceitos organizados em três grupos são: experiência e imaginação, imaginação e moralidade e moralidade e interesse próprio. A conclusão, de acordo com Adam Smith, é que The Wealth deve ser lido à luz do TSM; a mão invisível retribui a moralidade real, a economia e a moral se reúnem sem nenhum conflito sob a justificativa da ordem social fornecida pelo mercado.

PALAVRAS-CHAVE: Pensamento econômico, Adam Smith, moralidade.

ABSTRACT: The purpose of this paper is to show that Adam Smith's work is indeed unified as can be seen from the fundamental concepts pervading both The Theory of Moral Sentiments and The Wealth of Nations. This approach opposes the canonical reading of Adam Smith's work, in the sense that it links together four key concepts nested parities in a successive chain of three intersecting groups leading, ultimately, to the unified understanding of his contribution, apparently disperse into several independent pieces. The four concepts organized into three groups are: experience and imagination, imagination and morality and morality and self-interest. The conclusion is that, according to Adam Smith, The Wealth must be read in the light of the TMS; the invisible hand feeds back on the actual morality, economy and moral come together without any conflict under the justification of the social order provided by the market.

KEYWORDS: Economic thought, Adam Smith, morality.

JEL Classification: B1.

\footnotetext{
* Professora do Departamento de Economia da Universidade Federal Fluminense-UFF, Rio de Janeiro/ RJ, Brasil. E-mail: aganem@terra.com.br.
} 
Neste momento de crise das idéias, em que dogmas são derrubados e a razão crítica se contrapõe ao pensamento único na economia, a obra de Adam Smith se reafirma como uma fonte inesgotável para novas e profícuas reflexões. Reler e recuperar esta obra na totalidade, indagar do seu sentido unitário maior ou aceitar sem temor a impossibilidade de obter para a economia o recorte disciplinar almejado, são alguns dos desafios que a releitura provoca e que funcionam como um alerta ao pensamento crítico contra a idéia de uma história do pensamento cumulativa progressiva, ratificada a cada passo pelo que foi canonizado como verdade inquestionável.

Adam Smith forneceu uma explicação decisiva para a lógica dos fenômenos coletivos a partir de uma démarche individual. Ele concebeu a ordem social como uma emergência que harmoniza o caos potencial dos interesses individuais e os traduziu em bem-estar para a sociedade recorrendo para tal única e exclusivamente à imponderável e complexa ação dos indivíduos. Uma solução harmoniosa que supõe a dissipação aparente de conflitos próprios de uma sociedade hierarquizada e dispensa, na sua explicação, o príncipe. $\mathrm{O}$ mercado assim entendido representa a própria viabilização da ordem social, seu operador último, sua forma de organização social. Uma solução genial que colocou Smith dentro da história das idéias da humanidade como um dos grandes pensadores da modernidade, superando a fórmula do contrato fornecida pela filosofia política nos séculos XVII e XVIII.

A partir dessa solução, duas leituras da obra surgiram, dando origem ao chamado problema Adam Smith, uma das questões dentro da história do pensamento econômico que mais se consumiu tinta e energia nestes últimos dois séculos. Das Adam Smith Problem, assim denominado pela Escola Histórica Alemã teve seu início polêmico na segunda metade do século XIX e vem sendo sistematicamente tratado por estudiosos da história do pensamento econômico. Nestes últimos vinte anos, no entanto, esta questão tem suscitado um acalorado debate, com incontáveis artigos e reflexões. Vivienne Brown, ${ }^{1}$ no seu excelente survey, atesta que no último quartel pelo menos duzentos textos foram escritos sobre a obra dele, numa tentativa de relê-la inferindo novas e profícuas interpretações. Além disso, a Teoria nesta última década, foi reeditada e traduzida em quase todas as línguas do mundo acadêmico.

A primeira tese sobre a obra do autor defende a ruptura de seu pensamento e, portanto, a existência de dois universos conceituais que não dialogam: o tratado da moralidade, de um lado, o discurso sobre a economia, de outro. O mercado é entendido como um locus de troca, embrião da forma rigorosa da ordem eficiente e ótima do modelo canônico walrasiano de equilíbrio geral. A Teoria dos Sentimentos Morais é via de regra considerada uma obra da imaturidade e do devaneio do filósofo, totalmente dispensável para o entendimento da Riqueza, tratada como a sua única e grandiosa obra. A segunda corrente explora o sentido unitário e de

\footnotetext{
${ }^{1}$ Consultar V. Brown. in "Mere Inventions of the Imagination: a Survey of Recent Literature on Adam Smith”, Economy and Philosophy, no 13, 1999.
} 
continuidade da obra, resgata a competência filosófica do autor e torna manifesta a idéia de que a economia nasce sob a paternidade de um filósofo moral aproximando a economia da moral. Finalmente, ilumina a Riqueza com os escritos filosóficos da Teoria e tenta estabelecer uma relação conceptual entre as duas obras.

Até hoje, no entanto, se caminha no sentido de se achar uma articulação mais clara entre A Teoria dos Sentimentos Morais e A Riqueza das Nações. Que sorte de relação seria essa? O que significa estabelecê-la? Que consequiências essa relação traz para o entendimento da natureza da economia? Afinal Adam Smith é o primeiro autor a recortar o espaço disciplinar ou foi o autor que abriu as possibilidades concretas para se conciliar ética, economia e política? ${ }^{2}$

Neste trabalho parto da hipótese de que a obra smithiana revela uma indubitável continuidade metodológica e um belo sentido unitário. Para tecer as relações entre a sua filosofia moral e a economia sugiro sublinhar os conceitos que perpassam a Teoria e a Riqueza, de modo a construir sua unidade estabelecendo claramente as relações existentes entre as duas obras. Nesse objetivo deixo o autor falar e recorro pouco a textos secundários. Alerto também que meu ponto de partida é a TSM, pois estou convicta de que a maior parte das pistas para entender a unidade estão nela colocadas. O trabalho articula quatro conceitos que me parecem chaves entre si e que fornecem o sentido unitário das duas obras, apresentados em três movimentos articulados, cada qual se completando no anterior, de modo que o último encerra todos os anteriores. São eles: experiência e imaginação, imaginação e moralidade e moralidade e interesse.

\section{EXPERIÊNCIA E IMAGINAÇÃO}

O empirismo, tal qual foi concebido pelos modernos, recupera a historicidade dos sujeitos e as sensações como fonte de conhecimento e fonte sábia da ação humana. São, por sua estrutura, um verdadeiro libelo às idéias inatas do racionalismo cartesiano. As regras metódicas do mestre da razão, Descartes, libertam o sujeito do dogmatismo da explicação divina, instaurando a dúvida e a inquietude. Seu método foi considerado propulsor para que os modernos pudessem enfrentar pelo

\footnotetext{
${ }^{2}$ Em trabalho anterior procuro resgatar a dimensão filosófica de Adam Smith trazendo o autor, a obra e o nascimento da economia para o campo da filosofia de onde as idéias e as influências foram germinadas. No quadro da história das idéias sublinho a importância da questão central da modernidade, que foi a de indagar sob a possibilidade de explicar a sociedade auto-instituída, fundada no homem, e portanto independente da explicação divina. A partir desse exercício de volta ao passado e do esboço do quadro intelectual da modernidade observa-se que a solução de Adam Smith, embora esteja no âmbito da economia, consiste numa brilhante resposta à uma questão filosófica, ocorrendo uma interlocução com grandes autores da modernidade como Hobbes, Hume, Mandeville, Montesquieu e Locke. Isso significa que a solução da mão invisível de Smith só pode ser compreendida na sua real extensão se levarmos em conta a filosofia política e moral dos séculos XVII e XVIII, sublinhando o diálogo interdiscursivo, a assimilação conceptual e mesmo os conflitos que se estabeleceram nesse quadro de idéias (Ganem, 2000).
} 
conhecimento o entendimento de uma sociedade laica que agora deverá construir seu próprio destino. No entanto, paradoxalmente, esse mesmo esprit géométrique que ajudou a desvendar as leis físicas do universo, ao fornecer uma fórmula racional e um método universal para a direção do espírito e do conhecimento, constituise numa prisão, posto que assentado na força ilimitada da razão. Esta ditaria regras rígidas não apenas para o conhecimento mas para a moralidade considerados também inatos, apriorísticos (Descartes, 1959).

A filosofia empirista, na contramão desse método apriorístico, foi mais profícua para a análise da ordem social. Nos legou, Locke, Hume e Hobbes ${ }^{3}$, para citar alguns filósofos anglo-saxãos como Adam Smith, pai da economia política. Com este último a filosofia empirista e moral anglo-saxônica chega à sua plenitude explodindo em considerações que permitem um fino acabamento do comportamento humano. Tomadas as devidas diferenças, essa escola pretendia para a ciência social o mesmo que Newton ${ }^{4}$ conseguiu para a ciência natural: uma teoria geral da moral da política e da sociedade assentadas em bases empíricas. Sua vocação empirista

\footnotetext{
${ }^{3}$ Vários conceitos e idéias foram assimilados e compuseram não apenas o quadro conceptual analítico de Adam Smith, como deram substancia para o entendimento do que seria o ideário liberal. Tendo como ponto de partida o direito liberal, que garante o direito à vida, à liberdade e à propriedade (Hobbes e Locke) a ordem social estaria assentada na paixão de ganhar dinheiro, de acumular infinitamente, uma paixão calma, estável e universal (Hume), livre da idéia do vício e do pecado (Mandeville). O mercado em Adam Smith como fator de integração supera o comércio entre as nações (Montesquieu) e se traduz no próprio mecanismo de organizacão da sociedade liberal descartando definitivamente a explicação da emergência da ordem pelo contrato (Hobbes). Locke em Dois Tratados do Governo desenvolve a doutrina da propriedade no seu estado de natureza, elemento fundamental de sua teoria contratualista e base para compreensão do direito liberal. Sua construção teórica fornece a pré-condição pelo direito (ponto de partida jurídico-institucional) para que Smith possa pensar a solução da ordem social pelo mercado. Já Hobbes constrói axiomaticamente a passagem de um estado de natureza para a sociedade civil através do pacto social. Sua teoria do contrato ou a explicação da emergência da ordem pelo contrato instaura de uma só feita a sociedade, o Estado, as bases do direito liberal. Sua demonstração magistral valeu-lhe, como se sabe, o título de fundador da ciência política. Para Adam Smith a construção teórica de Hobbes funciona como um grande desafio. Hume embora colega de Smith, (ambos foram alunos de Hutcheson) influenciou decisivamente o autor. São dele, entre outras contribuições, três pontos cruciais: 1) a substituição do altruísmo de Hutcheson pelo conceito de simpatia, 2) a fundação da sociabilidade no desejo de ganho comum a todos os homens e 3)a exploração do sentimento e o julgamento de aprovação sublinhando a necessidade de se levar em conta na análise social as relações intersubjetivas (Ganem: 1993, 2000).

${ }^{4}$ A influência do mecanicismo newtoniano em Adam Smith pode ser interpretada como a edificação de sua filosofia moral e de sua economia política sobre o modelo da ciência newtoniana ou, em outros termos, a idéia de deduzir os fenômenos de um pequeno número de princípios. Sobre sua concepção harmônica e conectada do universo, Adam Smith nos diz: Todas as pequenas partes que coexistem no universo se adaptam a perfeição e contribuem para compor um sistema único e interconectado... (...). Ob Mundo... tudo que é adequado para ti o é pra mim... (Smith, TSM, 507). (Grifos nossos). Essa influência newtoniana no entanto deve ser relativizada pois foi usada por Buckle (1861) e depois por Skarzinski (1878) para fundamentar a idéia de que Adam Smith teria aplicado o método dedutivogeométrico, isolando elementos e portanto separando o universos da moral do universo do social. Essa análise além de defender a ruptura da obra incorre no equívoco de filiar o filósofo empirista Adam Smith ao racionalismo do esprit géometrique dos modernos. (Ganem, 1998, Raphael e Macfie, 1976, Bertrand 1993) Sobre a influência de Newton em Adam Smith, ver (Redman: 1993).
} 
tanto está presente nas suas considerações éticas, alicerçando-as no plano da intersubjetividade dos indivíduos, como na sua análise dos problemas correntes da ordem liberal, perscrutando na factualidade a origem da Riqueza das Nações. A inteligibilidade da ordem social liberal que está presente na sua solução pelo mercado passa pela observação, pela experiência, pela análise concreta do comportamento humano, pelo entendimento de uma subjetividade construída socialmente. Seu ponto de partida, o indivíduo, ou homem como ele realmente é, herança de realismo inaugurado por Maquiavel, atesta sua preocupação em entender a paixão que o move. A universalidade da paixão humana expressa no desejo de ganho ou numa vontade de melhorar a sua própria condição, que Adam Smith herda de Hume garante a possibilidade do nascimento da economia, posto que fornece os microfundamentos de uma ordem, articulando interesse privado ao interesse coletivo. Nada apriorístico, axiomático, hipotético, com idéias inatas ou regras fixas de moralidade e de comportamento. Uma verdade ligada à historicidade, uma verdade não mais no plano puramente lógico, mas estabelecida a partir do vínculo ético. Ao trasladar a verdade do plano puramente lógico, racional, para o plano vital, ocorre uma adequação entre verdade e vida mediada pela ética. A verdade passa a ser adequação do pensamento à realidade. Como para o autor não há um sentido moral inato, torna-se impossível definir regras invariáveis para as regras sociais, essas nascidas, portanto, das experiências privadas.

A partir da experiência, o sujeito smithiano pratica o segundo grande aspecto presente na TSM que é o exercício da imaginação. Só a partir da experiência podemos formar alguma idéia do que se passa na mente do outro, podemos nos colocar no lugar do outro. Só por meio da imaginação nos é possível conceber quais são as suas verdadeiras sensações. Imaginar-se no lugar do outro, vivenciar uma situação sentindo uma situação análoga ou colocando-se no lugar do outro é o ponto de partida da análise que Smith faz do indivíduo. Nas palavras do autor: “ $A$ imaginação permite nos colocarmos na posição do outro, padecer seus sofrimentos, entrar por assim dizer em seu corpo e chegar a ser, em alguma medida, uma única pessoa, formando assim uma idéia de suas sensações, sentindo algo parecido, embora de intensidade menor." (Smith, TSM: 50).

Reconhecido esse ponto de partida empírico, adentramos na complexidade da análise social de Adam Smith, que é a possibilidade da mudança de posições imaginárias. Esta mudança de papéis é a fonte real do interesse que mostramos por sua sorte, experiência se traduzindo no fio condutor para que seja possível a imaginação funcionar. Muitos autores recorreram à idéia do teatro para ler a TSM, idéia explorada a partir do trabalho de Marshall. ${ }^{5}$ Cada participante para Smith na TSM exerce dois papéis que se trocam simultaneamente ator/espectador ou espetáculo/

\footnotetext{
${ }^{5}$ Marshall, professor de literatura de Yale, publica, em 1984: Adam Smith and Theatrically of Moral Sentiments. Sua idéia de recuperar o teatro como forma de compreender a ordem social e aplicá-lo na TSM foi depois retomada por Dupuy (1992), Todorov (1996), Justman (1996) entre outros. Toda a TSM torna-se palco para que a angústia das pessoas se manifeste quando estas são colocadas sob o olhar do outro no palco: elas provocarão simpatia, elas serão aprovadas? Além do jogo de duplos ator-
} 
espectador. $\mathrm{O}$ ator age, sofre, sente, vivencia uma situação. O espectador colocase, através da imaginação, no lugar do ator e quando não existe a figura do espectador o ator ocupa efetivamente, pela imaginação, seu lugar, observa-se como ele o faria e encarna as normas sociais vigentes. Ao nos imaginarmos no lugar do outro, sensações nos sobrevêm: primeiro os sentimentos e os juízos se formam. Imagino, sensibilizo-me, identifico-me, aprovo. Todos esses elementos vêm juntos. Em contrapartida, aquele que age ou que sofre deseja que se simpatize com ele, quer que o aprovem, tem o desejo imperioso de ser aprovado. A prerrogativa de se vivenciar uma situação trocando os papéis, se preocupando, se identificando com a ação do outro, só é possível através da imaginação e afirma a idéia huminiana de que "os espíritos dos homens são espelhos uns para os outros", o que significa que o homem não vive isolado, o homem está constantemente frente a um espelho. Nas palavras de Adam Smith: "Suponhamos que somos espectadores de nosso próprio comportamento e tratamos de imaginar que efeito isto produz em nós. Este é o unico espelho mediante o qual podemos, em alguma medida, controlar com os olhos dos demais a correção de nossa conduta" (Smith, TSM: 230).

O exercício da imaginação que se traduz no colocar-se no lugar do outro e vivenciar, portanto, uma situação introduz uma sofisticação na análise da explicação da ordem social. Este sujeito que tira a sua substância do reconhecimento do outro via relações sociais (miméticas) mostra que o vínculo do homem com a verdade é um vínculo ético. Veremos que a experiência e a imaginação não são apenas dois pontos de partida da TSM, mas conceitos e perspectivas de análise que estão preservados na obra de Smith, marcando desde sua origem a idéia de um sujeito distante do homem econômico racional. O fundamento empírico fornece os elementos da contingência, das possibilidades de se entender e atuar no mundo real. Seu desejo de compreendê-lo ligado à possibilidade da imaginação na troca de papéis o aproximam de Keynes via Hume. ${ }^{6}$

Ao identificar uma incompletude do homem, uma não auto-suficiência e portanto uma necessidade intrínseca do outro ${ }^{7}$, Smith nos mostra a importância de se

espectador, o ponto nevrálgico do vínculo entre duas pessoas passa por uma ação, um ato que pode provocar ou não admiração, aplauso ou simpatia em última análise (Ganem, 2000).

${ }^{6}$ Para Keynes a única conduta individual num mundo de incerteza é a de imitar os outros. Através da lógica da especulação financeira a imitação mútua ou o processo mimético, estabelece um jogo de espelhos huminiano de contágio. Embora exista em Smith a herança dessa relação espelhar, é certo que ele não se limita a definir as relações sociais como imitativas. Smith mostra que existe uma relação do homem com a sua própria conduta, sendo essa última uma conduta social. Existiria ai uma influência do social no sujeito que interiorizaria normas e uma modificação na ação do sujeito a partir daí. Partilho da opinião de Dupuy que chama a isso uma boucle auto-referencielle que liga o sujeito a ele mesmo via o social, o que ele chama precisamente de "individualismo metodológico complexo" (Dupuy, 1992).

\footnotetext{
${ }^{7}$ Esse é um dos elementos mais fortes da estrutura teórica de Dupuy que alem de explorar essa radical necessidade do outro, a intersubjetividade que tece as normas sociais, ele apresenta um interessante paradoxo desse sujeito incompleto, que vive do olhar do outro sempre inclinado a se perder nos espelhos. "O espectador é externo e indiferente porque não é ele que sofre, mas interno e implicado porque tende a se simpatizar.” (Dupuy,1992: 150).
} 
levar em conta a intersubjetividade e sociabilidade presente na emergência de regras morais, reguladoras dos processos sociais. Estes pontos teóricos distanciam, sem sombra de dúvida, o sujeito smithiano do homem econômico racional, microfundamento da ordem neoclássica, agente atomizado e isolado que, através de sua racionalidade onisciente, dá respostas consistentes e automáticas na máquina ajustada do mercado.

\section{IMAGINAÇÃO E MORALIDADE}

É portanto a partir da experiência e da imaginação que os juízos éticos são formados. Esses últimos, ao derivarem da experiência, do convívio e da possibilidade do ator colocar-se no lugar do outro através da imaginação, afirmam incondicionalmente que as normas morais são produções sociais. Nas sábias palavras de Smith: "Avalio sua percepção pela minha percepção, seu ódio pelo meu ódio, sua razão pela minha razão, seu ressentimento pelo meu ressentimento, seu amor segundo o meu amor. Não tenho nem posso ter outra forma de julgá-los." (Smith, TSM: 66). Nessa passagem também elucidativa, o autor afirma: "Assim é como se formam as regras gerais da moralidade. Baseiam-se, em última instância, na experiência dos que aprovam nossas faculdades morais ou no nosso sentido de mérito e de correção." (Smith, TSM: 291, 292).

Para deixar claro que a convivência entre os homens é a fonte definidora da moralidade Adam Smith recorre a um princípio de nossa natureza que nos leva a entrar na situação dos outros e a compartilhar suas paixões. Ele o chamará, como Hume, de simpatia8: "A simpatia não é um sentimento egoísta. É verdade que quando me identifico com o seu pesar ou sua indignação é importante dizer que minha emoção se funda no amor próprio, porque assumo sua situação, coloco-me no seu lugar e sinto o que o outro sente em tais circunstâncias. Ainda que seja correto argumentar que a simpatia surge de uma imaginária troca de papéis, ela tem lugar na minha própria pessoa." (Smith, TSM: 554).

Por meio da imaginação o espectador pode compreender a situação do outro e manifestar um sentimento de simpatia. A simpatia do espectador pelo ator se dá pela experiência de uma situação que aquele vivencia no plano da imaginação. $\mathrm{O}$ espectador, através da imaginação, coloca-se na situação do ator, procura uma correspondência de sentimentos, identifica-se com ele. Este movimento das paixões corrobora a idéia subjacente na obra de Smith de que o homem não vive isolado, o homem vive em sociedade e todas as suas paixões são causa de novas paixões.

Mas voltemos à primeira idéia, a de que a simpatia não é um sentimento egoísta.

\footnotetext{
${ }^{8}$ A palavra simpatia vem do grego sympatheia e significa na sua origem conexão orgânica. Para Raphael e Macfie não seria esse o sentido que Adam Smith empresta ao termo. Para eles, Smith tanto quanto os estóicos, associa o conceito a um vínculo que tanto possibilita a compreensão do mundo social quanto ao entendimento do vínculo do indivíduo com ele mesmo através do auto-controle, conceito que dá substância ao homem prudente smithiano (Raphael e Macfie, 1976).
} 
O fato de Adam Smith deixar isso claro não autoriza a maior parte dos autores a reduzir a simpatia à benevolência ou à compaixão e a excluir a noção de amor-próprio que lhe é subjacente. Esta redução é a primeira e mais grave fonte de equívoco na leitura da TSM e impede a articulação entre esta e a Riqueza das Nações.

Embora tenha enfatizado a compaixão, o sentimento de se condoer com o sofrimento alheio, Adam Smith não a concebeu como esgotada pelo sentimento de benevolência. ${ }^{9}$ Ao não se ater à paixão da simpatia como compaixão e ao sublinhar a idéia de se colocar no lugar do outro em toda plenitude, Adam Smith abre espaço para outras paixões como a admiração, o amor e o amor-próprio..$^{10} \mathrm{O}$ amor, segundo ele, é a mais forte das paixões e é o veículo de uma virtude maior, o sentimento de justiça, este sim, indispensável à sociedade e muito mais importante do que a benevolência e mais virtuoso que a prudência. A prudência, fruto do autocontrole estóico e elemento do amor-próprio merece a aprovação enquanto que, a sabedoria e a justiça, virtudes próprias do homem magnânimo, merecem o aplauso. De toda forma, o amor a si mesmo, ou num plano mais geral o amor ao seu país, desloca o amor para centro da questão tornando-se o elemento chave para o entendimento da simpatia. $\mathrm{O}$ amor a si próprio é, portanto, o ponto de partida para o amor ao outro. Assim procedendo, Adam Smith inverte a máxima cristã de "ama ao próximo como a ti mesmo" para "ama a ti mesmo como tu amas o teu próximo" (Smith, TSM: 529).

Nesse sentido, sua idéia sobre o amor ao próximo, suprema virtude, estaria portanto mediada pelo amor-próprio. E este último, mesmo não sendo considerado uma paixão virtuosa deve ser entendido como motivo para a manifestação de sentimentos virtuosos e portanto, passível de produzir bem-estar para o outro. Adam Smith é enfático na crítica à estreiteza da análise de Hutcheson, “(...) que não consegue compreender que o amor-próprio possa ser impulso para atos virtuosos." (Smith, TSM: 529).

A leitura empobrecedora da real contribuição de Adam Smith, além de não conseguir ver a relação do amor-próprio com resultados virtuosos, produz um segundo equívoco, que é o de reduzir o amor-próprio ao egoísmo ou a uma vaidade ilusória. É interessante como o próprio Smith, no debate travado com Mandeville, tenta desfazer confusões, desvinculando a vaidade do egoísmo e vinculando-a ao conceito de amor-próprio, passível de ser construído no desejo que nos estimem, na aspiração a sermos objetos próprios de aprovação. Esse desejo de ser aprovado

\footnotetext{
${ }^{9}$ Alias, J.P. Dupuy esclarece quatro pontos importantes que concorrem para um melhor entendimento da noção de simpatia em Smith e que, regra geral, são fonte de confusões: 1) a simpatia não é a benevolência; Dupuy é enfático: "foi porque confundiram simpatia com benevolência que muitos caíram numa armadilha" (Dupuy, 1982: 150); 2) a simpatia supõe a separação dos seres, articulados entre si pela imaginação; 3) a simpatia não provem do egoísmo e 4) a simpatia não é o contágio (Dupuy, 1992b, 150/155).

${ }^{10}$ Esse conceito de amor-próprio Adam Smith recupera de Zenão que o entende com um princípio segundo o qual o homem deve conservar sua existência e a sua natureza no melhor e mais perfeito estado, isso significando fidelidade e respeito às leis da natureza (Smith, TSM: 486).
} 
funda o verdadeiro amor-próprio bem distante da vaidade mandevilliana destituída de conteúdo moral. Para o autor só deve ser merecedora de desprezo a vaidade ilusória aquela que não é merecida, aquela que não é fundada numa verdade ética (Smith, TSM: 534/546).

Nesse ponto e tendo essas questões levantadas sugiro explorarmos a idéia de adequação (propriety) ${ }^{11}$ presente em toda a TSM para melhor compreendermos a simpatia e a idéia de amor-próprio que ela contém. Essa noção permite, num primeiro plano, alcançar o sentido ético presente no tratado smithiano de moralida$\mathrm{de}^{12}$, num segundo, abrir para o entendimento das normas morais vigentes. Nessa obra, o autor não apenas define quais são as virtudes que o homem virtuoso e sábio deveria perseguir, como também nos fornece a possibilidade de entendermos o amorpróprio construído e expresso no desejo de aprovação e reconhecimento.

A adequação fornece novas luzes sobre o desejo imperioso de ser aprovado e, conseqüentemente, sobre a construção do amor-próprio. Mas o que significa esse desejo e que moralidade e conceitos básicos o norteiam? Se a intersubjetividade fica clara no exercício da imaginação, Smith não se limita a ela. Além de definir a relação social homem a homem o autor define uma relação do homem com a sua própria conduta, sendo esta última uma conduta social.

A importância do conceito de adequação está sublinhada em Zanini, ${ }^{13}$ que afirma tratar-se de um conceito que sai do âmbito da experiência e reemerge constantemente na obra de Smith. Mas esse critério já havia sido percebido pelo seu contemporâneo Dugald Stewart. Na TSM fica claro que o espectador aprova o que ele próprio acha justo e apropriado, ou seja, existe um sentimento de adequação (propriety) com o objeto que o provoca. Para Stewart o ponto alto da análise de Smith na TSM é sobre o mérito e o demérito. Fiel à idéias de Smith, Stewart afirma: "O grande objetivo de um homem sábio e virtuoso não é apenas agir de modo a obter a aprovação de quem rodeia, mas sim atuar de modo a converter-se no obje-

\footnotetext{
${ }^{11}$ A adequação é o principio pelo qual ator e espectador se adequam mutuamente numa tentativa de viverem de acordo com as normas morais vigentes. $\mathrm{O}$ ser humano se adequa porque carrega consigo o desejo de ser amado e de se constituir em objeto natural e apropriado do amor. No entanto, a adequação não é um princípio ditado por regras apriorísticas. Ao contrário, ela provem da experiência e depende de regras imprecisas, mutáveis, contingentes. Alias Adam Smith, sublinha que as únicas regras precisas são as da justiça, tão precisas e definidas como as regras gramaticais. (Smith,TSM: 573).

${ }^{12}$ A TSM é uma teoria do julgamento moral fundada sobre os sentimentos dos indivíduos. Os sentimentos dos homens entram em ressonância produzindo a ordem moral. E a simpatia, nesse quadro, assume a função de regulador ético que expressa um acordo em torno de determinadas regras morais na sociedade. A TSM introduziu uma complexidade na análise da moralidade e permitiu melhor a compreender a tessitura social. Por sua força teórica não passou despercebida a conterrâneos ilustres como Kant e Voltaire, para citar dois exemplos recolhidos pelo biográfo Ian S.Ross. O primeiro pergunta: "onde na Alemanha está o homem capaz de escrever tão bem sobre o caráter moral?” $\mathrm{E}$ Voltaire afirma: "não temos nada que se compare a ele e estou envergonhado por meus caros compatriotas”. (Ross, 1999: 279).

${ }^{13}$ Nas palavras do autor: "Come si può notare, non appena si retorni dal piano individuale al piano sociale, il criterio guida della propriety riemerge costantemente: esso è connnaturato all "ämbito dell'esperienza." (Zanini, 1997: 123).
} 
to justo e adequado da sua aprovação" (Stewart, 1998, 245). Adam Smith por sua vez é claro, não admitindo ambigüidades: "a natureza não apenas deu-lhe o desejo de ser aprovado mas também o desejo de converter-se no objeto justo e adequado da sua aprovação." (Smith, TSM: 236).

As regras morais podem ser internalizadas e expressas pelo homem dentro do peito. Logo fazemos uma mediação entre nós e o espectador imparcial, estabelecendo uma regra geral em que todas as ações que nos tornam depreciáveis devem ser evitadas. Ao internalizarmos o sentido de adequação, tornamo-nos espectadores imparciais de nossa própria conduta, verificando o seu mérito efetivo. Existiria em verdade um tribunal hipotético na nossa própria consciência, elemento construtor do nosso amor ao outro e do amor a nós mesmos. ${ }^{14}$

Mas o sentido de adequação não se esgota aí. Ele nos permite melhor compreender a diferença entre o homem prudente e o homem sábio. Adam Smith define o homem prudente como aquele capaz de agir com autocontrole, de cuidar da sua vida e do seu trabalho e de lutar por melhorar a sua própria condição. Ele tem amorpróprio e age em perfeita adequação (Smith,TSM: 382/389). No entanto, Adam Smith sublinha, em várias passagens que a prudência, embora respeitável, não é a virtude mais nobre. O homem sábio e virtuoso se destaca do prudente porque o primeiro tem o desejo magnânimo de melhorar a condição da comunidade. Nas suas palavras: "O indivíduo sábio e virtuoso está sempre disposto a sacrificar seu interesse particular em prol do interesse coletivo" (Smith,TSM: 421). Nesse sentido fica clara a distinção entre o homem virtuoso, o homem que deveria ser ou o homem do tratado moral da TSM e o homem prudente, o homem adequado à moralidade vigente, que age de acordo com ela para obter aprovação, em suma, o homem da Riqueza das Nações. O que deveria ser através das normas morais ideais e o homem como realmente é, objeto de uma importante questão da modernidade. Ao analisar tanto o homem prudente como a construção do amor-próprio na ordem social liberal nascente, Adam Smith nos mostra sua força analítica no entendimento da contingência, sublinhando magistralmente sua herança empirista.

Desfazendo confusões, devolvendo ao conceito de simpatia uma dimensão do amor-próprio que lhe faltava e sublinhando o sentido de adequação reunimos as condições para iluminar o conceito de interesse privado presente na Riqueza das Nações e, portanto, de explorar a possibilidade de unir as duas obras, objeto do próximo ponto.

\footnotetext{
${ }^{14}$ Para conseguir uma verdadeira satisfação moral, os indivíduos na visão smithiana deveriam tornarse espectadores imparciais de suas próprias condutas verificando seu mérito efetivo. Para tanto, exerceriam ao mesmo tempo os papéis de juiz e julgado, espectador e ator, expressão de razão e sentimento, homem externo e homem interno. (Smith, TSM: 230, 231, 235, 252). É interessante notar como a idéia de consciência associada à capacidade de julgarmos nossas próprias ações sublinha a idéia de sujeito e de consciência como produto de relações sociais. Ver a propósito (Raphael e Macfie: 1976) e (Raphael: 1975).
} 


\section{MORALIDADE E INTERESSE}

Vários autores tentaram entender a relação entre as duas obras se perguntando se existiria ou não uma possibilidade de união entre a moral e a economia na obra de Adam Smith. Essa discussão sobre se teria ocorrido uma ruptura ou permanecido uma unidade na obra está expressa na polêmica em torno do chamado "problema Adam Smith" ou Das Adam Smith Problem, assim intitulado inicialmente pela Escola Histórica Alemã. Em defesa da ruptura da obra e de dois universos irreconciliáveis, o da moral de um lado e o da economia, de outro, temos desde Skarzynski (1878) até o clássico texto de Jacob Viner de $1927^{15}$, passando obviamente pela leitura canonizada pelos neoclássicos.

Em defesa da unidade temos, além do testemunho de biógrafos e a descoberta de obras ${ }^{16}$ trabalhos como os de Morrow (1923), Raphael e Macfie (1976), Marshall (1984), para citar alguns nomes expoentes. Heilbroner (1982), por exemplo, defende a idéia de que o homem econômico da RN é o homem prudente da TSM. As paixões da vaidade e da prudência definidas na TSM se transformam numa condução calma dos negócios da RN. Heilbroner, identificando um sentido de continuidade entre as duas obras, afirma que Smith parte do homem primitivo no início da TSM e chega ao homem socializado ao final da TSM e início da RN.

Vários autores nessa última década tentam estabelecer relações entre as duas obras, entre eles Pack (1991), Todorov (1996), Justman (1996), Brown (1997), Zanini (1997), Witztsum (1998), entre outros. Esse último afirma que o self-interest da RN está baseado numa corrupção do sentido de moralidade definido na TSM: "Uma sociedade de auto-interessados pode ser considerada moralmente boa por pessoas auto-interessadas, o que não quer dizer que aos olhos de Adam Smith não ocorra uma degradação do sentido de moralidade". (Witztsum, 1998:511). Concordo no entanto com Dupuy quando este afirma que a maior parte dos autores, mesmo aqueles que defendem a unidade da obra, confundem interesse com selfinterest e, ao não trabalharem claramente com a noção de self-love, (que tanto está presente na simpatia como no interesse unindo os dois conceitos), terminam por criar uma falsa dicotomia entre interesse reduzido a egoísmo (self-interest), de um lado, versus simpatia reduzida a benevolência.

Quem nos fornece portanto a pista para continuar é Jean Pierre Dupuy (1992), que desfaz o terceiro equívoco que impediria uma possível ligação metodológica entre as duas obras. Este residiria na confusão em torno da noção de interesse e a

\footnotetext{
15 Jacob Viner utiliza o argumento de que na TSM existiria uma ordem harmoniosa da natureza concebida e guiada por um Deus bom, enquanto que na RN o que Adam Smith se depara são com as imperfeições baseadas na coleta de dados observados da realidade. Toda vez que Smith se deparou com um conflito entre sua generalização e seus dados, Smith teria abandonado a generalização. A Riqueza, para Viner significaria realismo e a expressão da ruptura com o pensamento metafísico-teológico-moral da TSM. (Viner, 1971).

${ }^{16}$ Baseando-se na publicação das Lectures on Jurisprudence foi veiculado o argumento, (em fins do século XIX) que, mesmo antes de sua partida para a França, Adam Smith já tinha formulado as bases teóricas da Riqueza e feito uma relação entre as duas obras a partir da idéia de que a ação econômica tinha sua fonte no self-love (Bertrand, 1993; Ganem, 2000).
} 
sua redução ao self-interest (egoísmo). Esse embroglio é apontado desde o início do debate em torno da ruptura ou unidade da obra e foi sublinhado pelos autores alemães da velha Escola Histórica Alemã. Eles, e em especial Knies, criticaram, já naquela época, entre 1840 e 1873, a leitura reducionista da noção de interesse. No interesse privado, para eles, poderiam coexistir tanto instintos egoístas de natureza conflitiva, como instintos sociais compatíveis com o amor ao próximo. ${ }^{17}$

Dupuy retoma essa idéia da complexidade da noção de interesse privado e sublinha a importância da noção de amor-próprio por detrás do interesse. O selfinterest é auto-referenciado e define a capacidade isolada do calculador racional que agencia meios em vista dos fins. O self-love tira o seu reconhecimento do olhar do outro e pode reconciliar interesse próprio com o outro A busca da riqueza privada ou do ganho material, ou desejo de melhorar a sua própria condição são frutos da vontade de atrair a aprovação dos outros e longe de criar laços nocivos à estabilidade social criam relações passionais estáveis (Dupuy, 1992).

Dentro dessa linha e na preocupação de sublinhar a importância do conceito de amor-próprio, fornecendo substância à noção de interesse privado, sugiro revisitarmos a frase mais conhecida de Adam Smith na Riqueza: "O homem necessita da ajuda de seus semelhantes e não pode esperar que estes lha dêem por mera bondade. Ser-lhe-á mais fácil consegui-la se puder explorar a seu favor o amor-próprio dos outros e lhes puder demonstrar que têm vantagem em fazer aquilo que lhes é pedido (...). Não é por generosidade que o açougueiro e o padeiro nos fornecem alimentos: fazem-no no seu próprio interesse. (...) Dirigimo-nos não ao seu espírito humanitário, mas ao seu amor-próprio e nunca lhes falamos das nossas próprias necessidades mas das vantagens que advirão para eles.” (Smith, RN, Livro I, Cap. I).

Uma leitura rápida dessa frase reforça a idéia de que a moral (via noção de simpatia) é descartada. E o amor-próprio, citado textualmente no segundo parágrafo sequer considerado. Uma dicotomia se instaura tendo como elementos opostos a simpatia, conceito nuclear e complexo da TSM, reduzida à benevolência e o interesse privado presente tanto na TSM como na RN, definido tautologicamente como egoísmo. Desaparecem as possibilidades de se associar a noções de interesse e simpatia a de amor-próprio ou tratar o homem que busca seu próprio interesse como um homem prudente, aquele que norteia sua vida e que tem "no desejo de melhorar a sua própria condição, um desejo calmo e desapaixonado." (Smith, RN, Livro II, Cap. II), mas igualmente adequado: “A pessoa prudente sempre será aprovada e recompensada pela aprovação total do espectador imparcial ou do representante dele, o homem dentro do peito" (Smith, TSM: 385). Esse desejo de ser aprovado e que dá consistência ao interesse e que para Smith deve ser mantido dentro das regras da prudência e da justiça não é nem vicioso (Mandeville) nem destrutivo (Hobbes), mas algo louvável e portador de felicidade, pois o indivíduo deve ter consideração com o seu próprio interesse e felicidade, fundo sobre o qual

\footnotetext{
${ }^{17}$ Existiriam dois instintos na natureza humana que ordenariam o interesse privado: o selbstlieb que seria um comportamento de conservação compatível com o amor ao próximo e portanto fonte da moral e o selbstsucht que seria de natureza essencialmente conflitiva (Bertrand, 1993).
} 
se alicerça seu amor a si mesmo (Smith TSM: 530). O homem prudente que se preserva é calmo, é em última análise, um homem adequado e prático. ${ }^{18}$ Seus interesses, sua tendência à troca se vinculam a um sentimento de preservação de amor a si mesmo ou num desejo imperioso de ser aprovado o que sugere um esforço de adequação para obtenção da aprovação. Esta moralidade que se impõe e que se realimenta dos julgamentos probatórios é o veículo forte da análise da sociabilidade. O recurso às regras morais é o elemento decisivo para a compreensão da inteligibilidade da ordem social do mercado que Adam Smith propõe.

Para concluir, retomo meu ponto de vista sobre o sentido de adequação e a construção do amor-próprio numa sociedade hierarquizada, dividida. A pista está na TSM. Nas contundentes palavras do autor: “(...) é porque os homens são inclinados a manifestar simpatia pelas nossas alegrias e não pelas nossas aflições que nós dissimulamos nossa pobreza e sublinhamos nossas riquezas. Nada é mais humilhante que expormos nossa miséria aos olhos do público e sentir que nossa situação é visível para todos... É por isso que perseguimos a riqueza e escondemos a pobreza.” (Smith, TSM: 123).

Adam Smith dedicou um capítulo de sua obra à corrupção dos sentimentos que é ocasionada pela disposição dos homens em admirar os ricos e ignorar os pobres. Este capítulo cujo titulo é auto-explicativo - "Da corrupção de nossos sentimentos morais ocasionada pela disposição em admirar os ricos e os grandes e a desprezar os pobres e de baixa condição" - foi introduzido na TSM em 1781, cinco anos após ter publicado a Riqueza. Nele, entre outras passagens da Teoria Smith afirma, não sem acidez, crítica ou pesar que "a propensão dos homens a simpatizar com a alegria é muito mais intensa do que com a tristeza ". Ou que "o rico faz glória de suas riquezas e o pobre tem vergonha e dissimula sua pobreza"... (Smith, TSM: 138). Apesar de a TSM se constituir num Tratado sobre a moralidade, isto é, do que "deveria ser”, das relações morais ideais entre os homens, o autor está preocupado em compreender estas relações numa sociedade hierarquizada, ainda que, para ele, estas lhe pareçam mesmo que inaugurais de uma nova sociedade, um tanto perniciosas e já deterioradas. Embora uma moralidade deteriorada (nesse ponto, concordo com Witztum: 1998), é essa moralidade que fala de admiração ao rico e desprezo do

${ }^{18}$ Para explicar essa perspectiva prática dos homens, Smith nos diz: "a preocupação com a nossa felicidade nos recomenda a prudência” (Smith, TSM: 463). E para tal recorre aos estóicos: "a doutrina dessas virtudes imperfeitas mas alcançáveis constituiu o que poderíamos denominar de moralidade prática dos estóicos." (TSM: 511). Em seguida, entretanto, marca sua diferença analítica sublinhando a mediação do espectador imparcial: "Os fatos que por natureza nos afetam, a nossos amigos, a nossos pais, são os fatos que animam nossos desejos e aversões, esperanças e temores, alegrias e pesares. Se essas paixões se tornam avassaladoras a natureza nos fornece uma adequada correção. A presença real ou imaginária do espectador imparcial, a autoridade do homem dentro do peito está sempre a mão para intimidá-las e reduzi-las ao tom e temperamento apropriados de moderação.” (TSM: 511) (grifos nossos). O sentido prático e o sentido de adequação estão presentes, mas estão permeados pela figura imaginária ou real do espectador imparcial que cumpre o papel de interiorizar as normas vigentes apontando os caminhos para uma vida adequada e feliz. Ver a propósito, a parte VII da TSM, onde Smith dialoga com os principais filósofos morais deixando claro tanto suas identificações como suas divergências teóricas. 
pobre que ele pretende dar conta. E será através dessa moralidade que admira o rico e despreza o pobre que se torna possível compreender em toda a sua extensão e complexidade o sentido de adequação e a idéia de que sujeitos e juízos morais, ambos são construídos socialmente e que eles contribuem para a estabilidade dos processos sociais. Pelo conceito de adequação torna-se possível aproximar a moral burguesa vigente às relações capitalistas nascentes e sublinhar as regras morais como operador social, tão importante quanto à mão invisível. Através do conceito de adequação podemos reconciliar moral e economia na obra de Adam Smith.

Recuperando os elementos conceituais que estão presentes em Adam Smith e que permitem uma leitura unitária de sua obra, fechamos finalmente o ciclo proposto por esse trabalho. A experiência como ponto de partida permite que o sujeito smithiano exercite a sua imaginação, vivenciando situações que não são as suas, colocando-se no lugar do outro. A troca de papéis que pode ocorrer a partir daí introduz a idéia de um jogo de espelhos nas relações sociais e carrega consigo a idéia central da TSM, de que os homens em sociedade tiram a sua substância do reconhecimento e da aprovação do outro. Os juízos éticos se formam a partir dessas experiências intersubjetivas, afirmando que é da convivência entre os homens que surgem as regras de moralidade. O princípio da simpatia, que nos leva a compartilhar paixões, permite também que se explore a paixão maior - o amor - e, a partir dela, o amor-próprio. O princípio da adequação fornece luzes sobre o desejo imperioso de ser aprovado que marca não apenas o homem sábio e virtuoso, mas o homem prudente da RN, capaz de agir com autocontrole e que luta para melhorar a sua própria condição. $\mathrm{O}$ interesse privado, conceito nuclear da Riqueza, longe de ser associado ao self-interest é identificado ao self-love. Os interesses, ao invés de se esgotarem na idéia de self-interest, isolados auto-referenciados são impulsionados pelo amor-próprio, que tem como idéia essencial sua incompletude, sua abertura para o olhar do outro, dependendo radicalmente do reconhecimento do outro. O homem prudente, capaz de melhorar a sua própria condição, age em perfeita adequação com as regras morais vigentes e constrói seu amor-próprio a partir daí. O mesmo elemento que o impulsiona a melhorar sua própria condição fornece as bases para o alimento e construção de seu amor-próprio. O desejo de ganho, de obter sucesso, riqueza e poder, alicerçado pelas normas vigentes, contribui para a estabilidade nesta ordem social hierarquizada. A mão invisível se realimenta da moralidade vigente, transformando-se não apenas num operador técnico, mas num operador social. Ao invés da guerra hobbesiana, uma ordem estável que é continuamente realimentada pela moralidade. O sentido unitário da obra é restabelecido. A Riqueza deve ser lida à luz da Teoria dos Sentimentos Morais. A economia nasce realmente sob a paternidade de um filósofo moral. A economia e a moralidade se reconciliam na explicação da emergência da ordem social do mercado em Adam Smith. A economia nasce em Adam Smith ligada indissoluvelmente à moral. 


\section{REFERÊNCIAS BIBLIOGRÁFICAS}

DESCARTES, R. (1959) Discours de la méthode. Paris: La Pléiade.

BERTRAND, P.(1993) “Histoire d'une Question — Das Adam Smith Problem”. Journée d'Études de l' Association Charles Gide pour L'Étude de la Pensée Economique, Paris.

BROWN, V. (1997) "Mere Inventions of the Imagination: a Survey of Recent Literature on Adam Smith". Economy and Philosophy, $\mathrm{n}^{\circ} 13$.

DUPUY, J.P.(1992a) Le Sacrifice e L' Énvie: Le Libéralisme aux Prises da la Justice. Paris: CalmannLévy.

DUPUY, J.P. (1992b): Introduction aux sciences sociales: logique des phénomenes collectifs, Paris: Ellipses.

GANEM A (1989) “A teoria neoclássica: a face econômica da razão positiva”. Literatura Econômica, IPEA, vol. 11, n 25.

GANEM, A (1993) “Théorie de l' Équilibre Général: le Mythe d'un Ordre Rationnel”. Paris XIII, Nanterre-Université, tese de doutorado (mimeo).

GANEM, A (2000) "Adam Smith e a explicação do mercado como ordem social: uma abordagem histórico-filosófica”, Revista de Economia Contemporânea, 4 (2), julho-dezembro: 9-36.

HEILBRONER, R. (1982) “The socialization of the individual in Adam Smith". History of Political Economy, $\mathrm{n}^{\circ} 14$.

JUSTMAN, S. (1993) “Regarding others”. New Literature History, ${ }^{\circ} 27$.

MORROW, G. (1923) “The significance of the sympathy in Hume and Adam Smith”. Philosophical Review, $\mathrm{n}^{\circ} 32$.

PACK, S. (1991) Capitalism as a Moral System: Adam Smith's critique of the Free Market Economy. Aldershot: Edward Elgar.

RAPHAEL, D.D. (1975) “The impartial spectator” in SKINER, A e WILSON, T (org.) Essays on Adam Smith. Oxford: Clarendon Press.

RAPHAEL,D.D.e MACFIE (1976) Introduction of The Theory of Moral Sentiments. Oxford: Clarendon Press.

REDMAN, D.A.(1991) “Adam Smith and Isaac Newton”. Scottish Journal of Political Economy, vol. 40 (2): 211-229.

ROSS,I (1999) Adam Smith: uma biografia. Record, 1999.

SMITH, A [1759] (1976) The Theory of Moral Sentiments. Oxford: Clarendon Press.

SMITH, A[1759] (1997) La Teoria de los Sentimientos Morales, version espanhola, Alianza Editorial, S.A, Madrid, 1997.

SMITH, A [1795] (1998) Ensayos Filosoficos, version espanhola, Ediciones Piramide, AS, Madrid.

SMITH A [1776] (1976) An Inquiry into the Nature and causes of the Wealth of Nations. Oxford: Oxford University Press.

STEWART, D.[1795] (1998) "Relacion de la vida y escritos de Adam Smith”. Ensayos filosoficos, Ediciones Piramide, S.A., Madrid.

TODOROV, T.(1996) "Living alone together". New Literary History, n 27.

VINNER, J. (1971) “Adam Smith e o laisser faire” in Spengler,J.e Allen,W. (Org.): El pensamiento economico de Aristoteles a Marshall. Madrid: Editorial Tecnos.

WITZTUM, A. (1998) “A study into Smith's conception of the Human Character: Das Adam Smith Problem Revisited". History of Political Economy, 30:3.

ZANINI, A (1997) Adam Smith: Economia, Moralle, Diritto. Edizione Scolastiche Bruno Mondadori, Milão. 